\title{
Tuning of protein-surfactant interaction to modify the resultant structure
}

\author{
Sumit Mehan, ${ }^{1}$ Vinod K. Aswal, ${ }^{1}$ and Joachim Kohlbrecher ${ }^{2}$ \\ ${ }^{1}$ Solid State Physics Division, Bhabha Atomic Research Centre, Mumbai 400 085, India \\ ${ }^{2}$ Laboratory for Neutron Scattering, Paul Scherrer Institut, CH-5232 PSI Villigen, Switzerland \\ (Received 30 July 2015; revised manuscript received 27 August 2015; published 15 September 2015)
}

\begin{abstract}
Small-angle neutron scattering and dynamic light scattering studies have been carried out to examine the interaction of bovine serum albumin (BSA) protein with different surfactants under varying solution conditions. We show that the interaction of anionic BSA protein $(p \mathrm{H} 7)$ with surfactant and the resultant structure are strongly modified by the charge head group of the surfactant, ionic strength of the solution, and mixed surfactants. The protein-surfactant interaction is maximum when two components are oppositely charged, followed by components being similarly charged through the site-specific binding, and no interaction in the case of a nonionic surfactant. This interaction of protein with ionic surfactants is characterized by the fractal structure representing a bead-necklace structure of micellelike clusters adsorbed along the unfolded protein chain. The interaction is enhanced with ionic strength only in the case of site-specific binding of an anionic surfactant with an anionic protein, whereas it is almost unchanged for other complexes of cationic and nonionic surfactants with anionic proteins. Interestingly, the interaction of BSA protein with ionic surfactants is significantly suppressed in the presence of nonionic surfactant. These results with mixed surfactants thus can be used to fold back the unfolded protein as well as to prevent surfactant-induced protein unfolding. For different solution conditions, the results are interpreted in terms of a change in fractal dimension, the overall size of the protein-surfactant complex, and the number of micelles attached to the protein. The interplay of electrostatic and hydrophobic interactions is found to govern the resultant structure of complexes.
\end{abstract}

DOI: 10.1103/PhysRevE.92.032713

PACS number(s): 87.15.-v, 87.14.E-, 82.70.Dd, 87.64.Bx

\section{INTRODUCTION}

Protein and surfactant together show rich phase behavior in aqueous solution because of their common amphiphilic nature [1-4]. The surfactant molecules are known to interact via electrostatic binding at low concentrations and cooperative binding at high surfactant concentrations [5-7]. Tuning of the interaction between protein and surfactant by different means leads to a wide range of applications of their complexes from cosmetics to pharmaceuticals to protein separation [8-11]. For example, in the protein separation process of sodium dodecyl sulfate-polyacrylamide gel electrophoresis (SDSPAGE) the interaction of surfactant with protein is used to unfold the protein through the formation of protein-surfactant complexes. Unfolded proteins are separated based on their mobility in polyacrylamide gel electrophoresis, which is directly dependent on the molecular weight of the protein $[8,10]$. Surfactants are also known to modify the properties of cosmetics, pharmaceuticals, and food products in terms of rheology, appearance, and taste [11-13]. The coating of surfactant-induced unfolded protein enhances the biocompatibility of nanoparticles for drug delivery [14]. The demanding applications as well as scientific interest of protein-surfactant systems require detailed understanding of the structure and interaction in these complexes.

The interactions of globular proteins with surfactants have been widely reported in the literature [15-23]. Proteins are usually charge stabilized and therefore they have strong interactions with ionic surfactants. Both cationic and anionic surfactants can interact with proteins because of the site-specific interaction of surfactants on the oppositely charged patches of the protein $[22,24,25]$. On the other hand, nonionic surfactants, because of the absence of any electrostatic interaction, can have only the hydrophobic interaction with proteins $[19,22,26]$. The differences in the interaction behavior of ionic and nonionic surfactants suggest that the protein-surfactant interaction is primarily driven by their electrostatic interaction. At low concentrations, the surfactant molecules individually bind to the protein, resulting in the expansion of the folded protein $[6,19]$. The protein unfolds beyond a critical aggregation concentration of surfactant, where the micellelike clusters of surfactants are formed around the hydrophobic patches of the protein [5-7]. These complexes are referred as bead-necklace structures [5-7]. There is also interest in knowing innovative ways by virtue of which an unfolded protein can fold back or prevent protein unfolding [16,27-29]. The competition of electrostatic and hydrophobic interactions plays an important role for this purpose [30,31]. This requires understanding of the role of each of these interactions. In this paper, we have looked into tuning of the protein-surfactant interaction to modify the resultant structure by varying the surfactant type, ionic strength of the solution, and mixing surfactants. The work has resulted in a useful method for the refolding of unfolded protein and prevention of surfactant-induced protein unfolding.

The model protein bovine serum albumin protein (BSA) with the surfactants anionic sodium dodecyl sulphate (SDS), cationic dodecyl trimethyammonium bromide (DTAB), and nonionic polyoxyethylene 10 lauryl ether (C12E10) has been used to study their complexes. The interaction of the protein with these different surfactants is examined with varying concentration of surfactant, ionic strength, and mixture of surfactants. The systems are characterized by small-angle neutron scattering (SANS) and dynamic light scattering (DLS). These two techniques can cover length scales suitable for measuring different structures formed in the protein, surfactant, and their complexes $[6,17,19]$. The easy possibility of contrast variation through isotope substitution makes SANS an excellent technique to study hydrogenous systems 
[21,32,33]. The measured scattering cross-section data in SANS provide both the structure and interaction under native conditions [32]. DLS is a complementary technique where the system is characterized by measuring the temporal intensity autocorrelation function [17].

\section{EXPERIMENTAL SECTION}

Protein [BSA (catalog no. A2153)] and surfactants [anionic SDS (catalog no. L4390), cationic DTAB (catalog no. D5047), and nonionic C12E10 (catalog no: P9769)] were purchased from Sigma-Aldrich. The stock solutions of protein $(10 \mathrm{wt}$ $\%)$ and surfactants $(400 \mathrm{mM})$ were prepared by dissolving the required weighed amounts of components in $20 \mathrm{mM}$ phosphate buffer at $p \mathrm{H}=7$. All the protein-surfactant complexes under study were prepared from the dilution of these stock solutions and in the presence of salt $(\mathrm{NaCl})$. The addition of salt is used to reduce the electrostatic interaction between different components. The samples were prepared in $\mathrm{D}_{2} \mathrm{O}$ (99.9 at. \% D), which provides better contrast for hydrogenous components (protein and surfactant) in neutron scattering experiments [33]. Small-angle neutron scattering experiments were performed at the SANS-I facility, Swiss Spallation Neutron Source SINQ, Paul Scherrer Institut, Switzerland [34]. The wavelength $(\lambda)$ of the neutron beam used was $8 \AA$ and the wavelength resolution $(\Delta \lambda / \lambda)$ was about $10 \%$. The scattered neutrons from samples were detected using a two-dimensional $\left(96 \times 96 \mathrm{~cm}^{2}\right){ }^{3} \mathrm{He}$ gas detector. Two sample-to-detector distances of 2 and $8 \mathrm{~m}$ were used to collect the data over a wave vector transfer [ $Q=4 \pi \sin (\theta / 2) / \lambda$, where $\theta$ is the scattering angle] range of 0.007 to $0.30 \AA^{-1}$. Samples were held in 2-mm-path-length Hellma quartz cells during the experiments. The measurements were carried out for a fixed concentration of protein (1 wt \%) and varying concentration of surfactants in the range of 0 to $100 \mathrm{mM}$. The effect of ionic strength has been studied by varying the salt concentration up to $0.5 \mathrm{M}$. The interaction of protein with mixed ionic-nonionic surfactants (SDS-C12E10 and DTAB-C12E10) is examined for different mole ratios of the two surfactants. All the measured data were corrected and normalized to absolute units of cross section using standard procedures [35]. DLS experiments were carried out using an SZ-100 particle size analyzer (Horiba, Japan) having a 10-mW-diode-pumped solid state laser at a wavelength of $532 \mathrm{~nm}$. The scattering angle was kept fixed at $173^{\circ}$ during the measurements. The choice of backscatter detection minimizes any contamination from dust particles and multiple scattering from the sample. The $Q$ value for DLS measurements is $0.0031 \AA^{-1}$.

\section{DATA ANALYSIS}

\section{A. Small-angle neutron scattering}

The differential scattering cross section per unit volume $(d \Sigma / d \Omega)$ as a function of $Q$ is measured in a SANS experiment. In the case of monodisperse interacting particles, $d \Sigma / d \Omega$ can be expressed as $[36,37]$

$$
\frac{d \Sigma}{d \Omega}(Q)=n P(Q) S(Q)+B
$$

where $n$ is the number density of particles, $P(Q)$ and $S(Q)$ are the form factor and structure factor, respectively, and $B$ is the incoherent background arising mostly due to the presence of hydrogen in the sample.

$P(Q)$ depends on the shape and size of particles. The ellipsoidal shape is commonly used as it can represent different shapes depending on the axial ratio, from spherical to rodlike and disklike particles. For an ellipsoidal core-shell particle, $P(Q)$ can be written as [38]

$$
\begin{gathered}
P_{e c s}(Q)=\int_{0}^{\pi / 2} P\left(Q, r_{1}, r_{2}\right) \sin \beta d \beta \\
P\left(Q, r_{1}, r_{2}\right)=\left[\left(\rho_{c}-\rho_{\text {shell }}\right) V_{1}\left\{\frac{3 j_{1}\left(Q r_{1}\right)}{Q r_{1}}\right\}\right. \\
\left.+\left(\rho_{\text {shell }}-\rho_{s}\right) V_{2}\left\{\frac{3 j_{1}\left(Q r_{2}\right)}{Q r_{2}}\right\}\right]^{2}, \\
j_{1}(x)=\frac{(\sin x-x \cos x)}{x^{2}} \\
r_{1}=R \sqrt{\sin ^{2} \beta+\varepsilon^{2} \cos ^{2} \beta} \\
r_{2}=(R+t) \sqrt{\sin ^{2} \beta+\varepsilon^{2} \cos ^{2} \beta}
\end{gathered}
$$

where $\rho_{c}, \rho_{\text {shell }}$, and $\rho_{s}$ are respectively the neutron scattering length densities of the particle core, shell, and solvent. The dimensions $R$ and $\varepsilon R$ are semiaxes and $t$ is the shell thickness of ellipsoidal particles. $V_{1}$ and $V_{2}$ are the volumes of the core and the core along with the shell, respectively. $\beta$ is the angle between the directions of semimajor axis and wave vector transfer. $j_{1}(x)$ is a first-order spherical Bessel function. The shape of the particle is spherical for $\varepsilon=1$, prolate ellipsoidal for $\varepsilon>1$, and oblate ellipsoidal for $\varepsilon<1$. The particles become rodlike when $\varepsilon \gg 1$ and disklike for $\varepsilon \ll 1$.

$S(Q)$ is decided by the interaction between the particles. It is unity for the dilute system $[S(Q) \approx 1]$. In the case of uncharged particles, they interact with the hard-sphere potential and $S(Q)$ has been calculated using the Percus-Yevic approximation [39]. For charged particles, $S(Q)$ has been calculated using a screened Coulomb potential under the rescaled mean spherical approximation. The particles are assumed to be rigid equivalent spheres of diameter $\sigma=2\left(a b^{2}\right)^{1 / 3}$ interacting through a potential as given by [40]

$$
u(r)=u_{0} \sigma \frac{\exp [-\kappa(r-\sigma)]}{r}, r>\sigma,
$$

where $\kappa$ is the Debye-Hückel inverse screening length and $u_{0}$ is the contact potential.

The protein-surfactant interaction has been modeled using the necklace model, which assumes micellelike clusters of surfactant randomly distributed along the unfolded polypeptide chain of the protein. The scattering cross section for such a system can be expressed as [5,6]

$$
\frac{d \Sigma}{d \Omega}(Q)=\frac{N_{1}^{2}}{N_{p} M}\left(b_{m}-V_{s} \rho_{m}\right)^{2} P_{m}(Q) S_{f}(Q)+B,
$$

where $N_{p}$ and $N_{1}$ are the number density of protein and number density of surfactant molecules participating in formation of protein-surfactant complexes. $V_{s}$ is the volume of surfactant molecules and $M$ is the number of micellelike clusters attached 


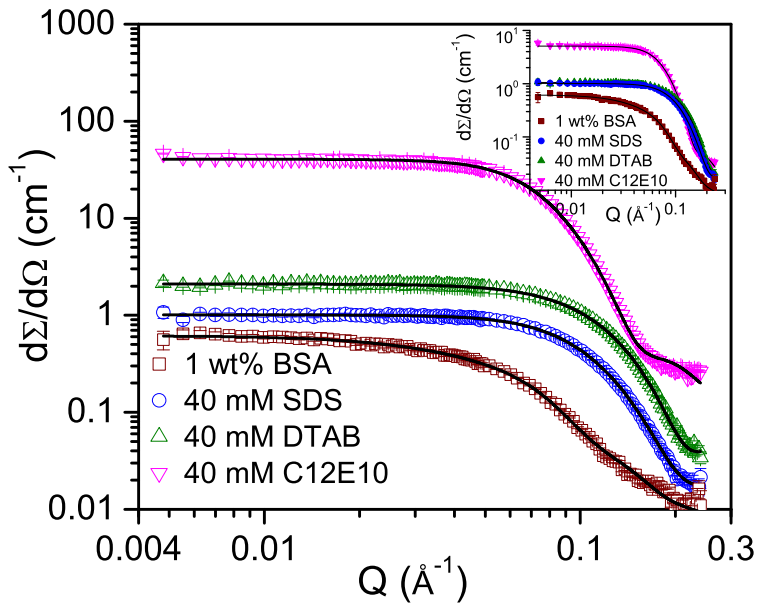

FIG. 1. (Color online) SANS data of $1 \mathrm{wt} \%$ BSA protein and $40 \mathrm{mM}$ of surfactants (anionic SDS, cationic DTAB, and nonionic $\mathrm{C} 12 \mathrm{E} 10)$ at $p \mathrm{H}=7$ and $0.2 \mathrm{M} \mathrm{NaCl}$ in $\mathrm{D}_{2} \mathrm{O}$. The data are shifted vertically for clarity. Inset shows the data without shifting.

to a polypeptide chain. The aggregation number of micellelike clusters in the complex is given by $N=N_{1} /\left(N_{p} M\right) . b_{m}$ and $\rho_{m}$ are the scattering length and scattering length density of surfactant molecules. $P_{m}(Q)$ denotes the form factor of a single micellelike cluster. Protein-surfactant complexes are usually characterized by mass fractals. For such a fractal structure, $S_{f}(Q)$ is given by $[5,41]$

$$
\begin{aligned}
S_{f}(Q)= & +\frac{1}{\left(Q r_{0}\right)^{D}} \frac{D \Gamma(D-1)}{\left[1+\frac{1}{(Q \xi)^{2}}\right]^{(D-1) / 2}} \\
& \times \sin \left\{(D-1) \tan ^{-1}(Q \xi)\right\},
\end{aligned}
$$

where $r_{0}$ is the building block radius, $D$ is the fractal dimension, and $\xi$ is the correlation length of the fractal structure. $\Gamma$ is a Gamma function.

The data have been analyzed by comparing the calculated model scattering with the experimental data. Corrections for instrumental smearing were made throughout the data analysis. The modeled scattering profiles were smeared by the appropriate resolution function to compare with the measured data. A nonlinear least-squares fitting program was used to optimize the fitted parameters in data analysis [39].

\section{B. Dynamic light scattering}

In dynamic light scattering, the temporal fluctuations in the scattering light intensity using a monochromatic light at a particular scattering angle are measured. The normalized intensity autocorrelation function is given as $[42,43]$

$$
g^{(2)}(\tau)=\frac{\langle I(t) I(t+\tau)\rangle}{\langle I(t)\rangle^{2}},
$$

where $I(t)$ is the scattered light intensity at time $t$ and $I(\mathrm{t}+\tau)$ the scattered light intensity at time $t$ plus a lag time $\tau$. These fluctuations in scattered light intensity depend on the diffusion coefficient of particles undergoing Brownian motion. $g^{(2)}(\tau)$ is related to the normalized field autocorrelation function $g^{(1)}(\tau)$ as

$$
g^{(2)}(\tau)=1+\beta\left|g^{(1)}(\tau)\right|^{2},
$$

where $\beta$ is the spatial coherence factor and depends on the instrument optics.

For a dilute system of monodisperse particles in suspension, the field autocorrelation function $g^{(1)}(\tau)$ is represented by

$$
g^{(1)}(\tau)=\exp (-\Gamma \tau)
$$

where $\Gamma$ is the decay rate and related to the diffusion coefficient of particles and the wave vector $Q$ as $\Gamma=D Q^{2}$. For a system of polydisperse particles, Eq. (12) modifies to

$$
g^{(1)}(\tau)=\int_{0}^{\infty} G(D) \exp \left(-D Q^{2} \tau\right) d D,
$$

where $G(D)$ is the distribution of particles with different diffusion coefficients about the mean value. The cumulant analysis method is used to calculate the mean value of

\begin{tabular}{|c|c|c|c|c|}
\hline Protein system & Shape & & tructural dimensio & \\
\hline BSA & Oblate ellipsoidal & $\begin{array}{c}\text { Semimajor axis } \\
R=42.3 \AA\end{array}$ & $\begin{array}{c}\text { Semiminor axis } \\
\varepsilon R=13.6 \AA\end{array}$ & $\begin{array}{l}\text { Effective radius } \\
\varepsilon^{1 / 3} R=29.0 \AA\end{array}$ \\
\hline
\end{tabular}
the diffusion coefficient $\left(D_{m}\right)$ and polydispersity index (PI)

TABLE I. The fitted structural parameters of SANS data of individual components of BSA protein and surfactants (anionic SDS, cationic

\begin{tabular}{|c|c|c|c|c|c|c|}
\hline \multirow[b]{2}{*}{ Surfactant system } & \multirow[b]{2}{*}{ Shape } & \multicolumn{5}{|c|}{ Structural dimensions } \\
\hline & & $\begin{array}{l}\text { Semimajor } \\
\text { axis } \\
\varepsilon R(\AA)\end{array}$ & $\begin{array}{l}\text { Semiminor } \\
\text { axis } \\
R(\AA)\end{array}$ & $\begin{array}{c}\text { Shell } \\
\text { thickness } \\
t(\AA)\end{array}$ & $\begin{array}{c}\text { Aggregation } \\
\text { number } \\
N\end{array}$ & $\begin{array}{l}\text { Charge } \\
\text { Z (e.u.) }\end{array}$ \\
\hline SDS & Prolate ellipsoidal & 28.6 & 16.7 & 5.0 & 95 & -23.8 \\
\hline DTAB & Prolate ellipsoidal & 20.5 & 16.7 & 5.8 & 68 & +19.7 \\
\hline C12E10 & Spherical & 17.3 & 17.3 & 12.2 & 62 & 0 \\
\hline
\end{tabular}
DTAB, and nonionic $\mathrm{C} 12 \mathrm{E} 10$ ) at $p \mathrm{H}=7$ and $0.2 \mathrm{M} \mathrm{NaCl}$ in $\mathrm{D}_{2} \mathrm{O}$. The aggregation number of micelles is calculated by dividing the micellar volume by the volume of surfactant molecule.

(a) $1 \mathrm{wt} \%$ BSA protein

(b) $40 \mathrm{mM}$ surfactants 
[44,45]. In this analysis, Eq. (13) is simplified to

$$
g^{(1)}(\tau)=\exp \left[-D_{m} Q^{2} \tau+\frac{\mu_{2} \tau^{2}}{2}\right],
$$

where the PI is given by the ratio of the variance $\left(\mu_{2}\right)$ to the square of the mean of the decay rate $\left(\Gamma_{m}=D_{m} Q^{2}\right)$.

The Stokes-Einstein relation correlates the hydrodynamic radius of particles to the diffusion coefficient as given by [42]

$$
R_{h}=\frac{k_{B} T}{6 \pi \eta D},
$$

where $k_{B}$ is Boltzmann's constant, $\eta$ is the viscosity of the solvent, and $T$ is the absolute temperature.

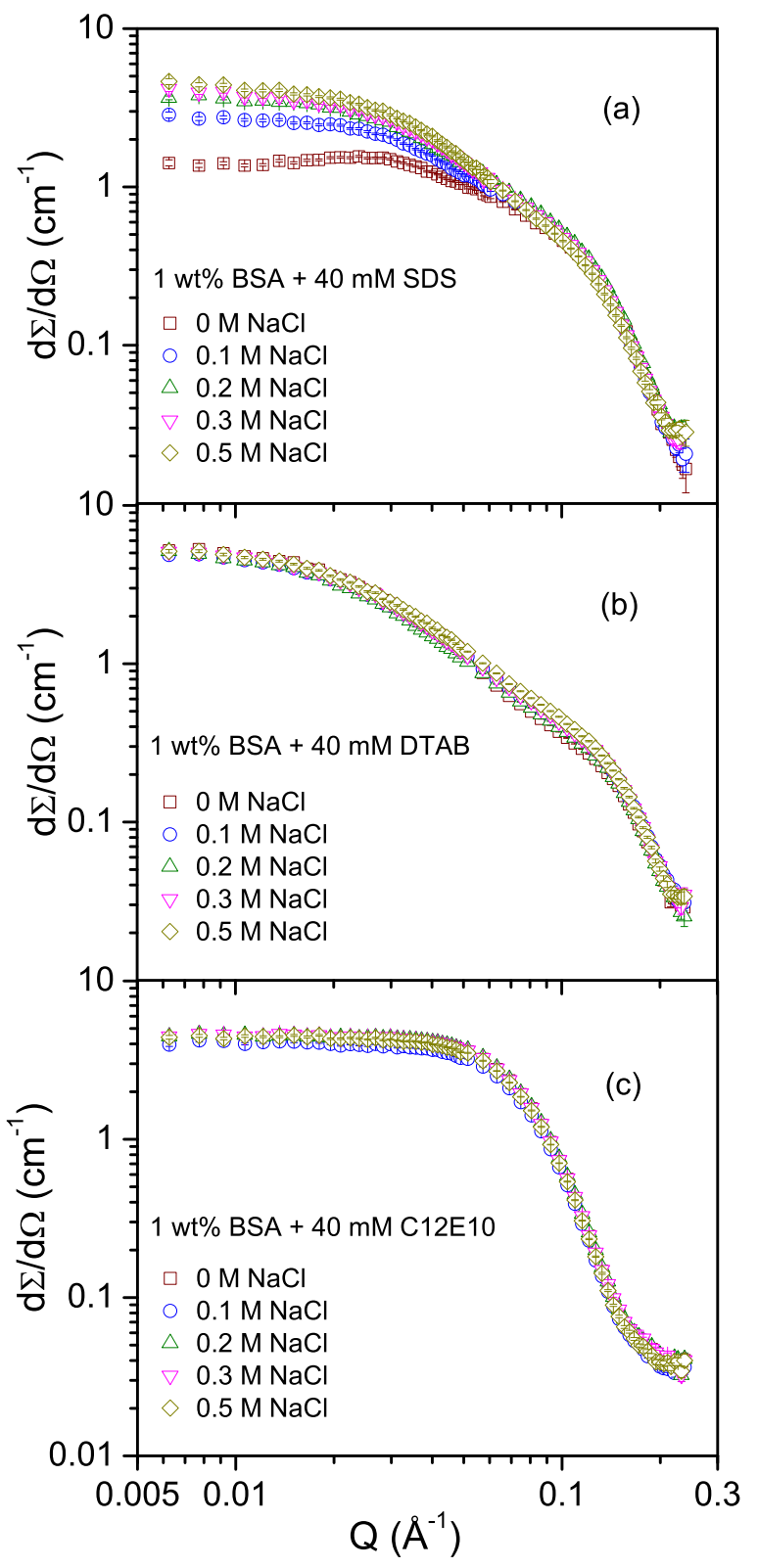

FIG. 2. (Color online) SANS data of $1 \mathrm{wt} \%$ BSA protein with $40 \mathrm{mM}$ of (a) anionic SDS, (b) cationic DTAB, and (c) nonionic $\mathrm{C} 12 \mathrm{E} 10$ surfactants for varying salt concentration from 0 to $0.5 \mathrm{M}$ $\mathrm{NaCl}$ at $p \mathrm{H}=7$ in $\mathrm{D}_{2} \mathrm{O}$.

\section{RESULTS AND DISCUSSION}

\section{A. Characterization of individual protein and surfactant systems}

SANS data from individual components 1 wt \% BSA protein and $40 \mathrm{mM}$ surfactants (anionic SDS, cationic DTAB, and nonionic C12E10) are shown in Fig. 1. The SANS data of BSA protein are similar to those of the dilute system, $S(Q) \sim 1$. The data are therefore fitted with the model of $P(Q)$ alone. It is found that BSA protein macromolecules are oblate ellipsoidal having semiminor and semimajor axes of 13.6 and $42.3 \AA$, respectively [46]. The charge on the BSA protein at $p \mathrm{H} 7$ is -16 e.u. In the case of micelles, unlike proteins, SANS data cannot be fitted by $P(Q)$ only and require some contribution from $S(Q)$. This could be because of the higher number density of micelles as compared to that of the protein in the respective systems. The data of ionic micelles (SDS and DTAB) are fitted with the $S(Q)$ of charged particles interacting through screened Coulomb interaction, whereas nonionic micelles of C12E10 are fitted by the hard sphere interaction $[39,40]$. The fitted parameters of the protein and different micelles are given in Table I. The ionic micelles are found to have the prolate ellipsoidal core-shell structure with semiminor axis, semimajor axis and shell thickness as 16.7, 28.6, and 5.0 $\AA$, respectively, for SDS and 16.7, 20.5, and $5.8 \AA$, respectively, for DTAB. ${ }^{28}$ The SDS and DTAB micelles have aggregation numbers of 95 and 68 with total charge on them -23.8 and +19.7 e.u., respectively. The lower effective size of the head group gives rise to a higher value of aggregation for SDS than DTAB. The C12E10 micelles are fitted with the $P(Q)$ of a spherical hydrophobic core and a shell of hydrophilic Gaussian chains around the core. The radius of the core is found to be $17.3 \AA$ and the radius of gyration of the hydrophilic chain $12.2 \AA$ [47-49]. The structural parameters of the protein and micelles as obtained are in good agreement with the literature [32,47-49]. The three surfactants used have different charged head groups attached to the same hydrophobic chain, which in the present study allows examining the role of electrostatic vs nonelectrostatic interactions in the protein-surfactant complexes.

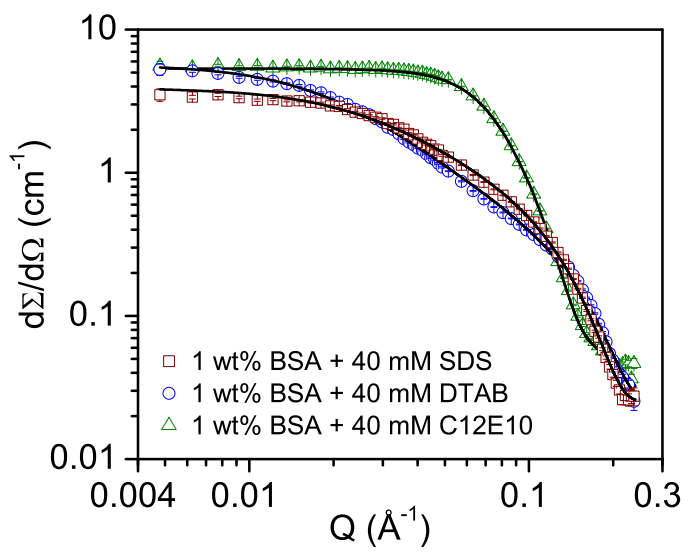

FIG. 3. (Color online) SANS data of 1 wt \% BSA protein with $40 \mathrm{mM}$ of anionic SDS, cationic DTAB, and nonionic C12E10 surfactants at $p \mathrm{H}=7$ and $0.2 \mathrm{M} \mathrm{NaCl}$ in $\mathrm{D}_{2} \mathrm{O}$. 
TABLE II. Fitted parameters of SANS data of protein-surfactant systems characterized by mass fractal structure representing bead-necklace model of their complexes.

\begin{tabular}{|c|c|c|c|c|c|}
\hline System & $\begin{array}{c}\text { Micelle } \\
\text { radius } \\
r(\AA)\end{array}$ & $\begin{array}{c}\text { Correlation } \\
\text { length } \\
\xi(\AA)\end{array}$ & $\begin{array}{c}\text { Fractal } \\
\text { dimension } \\
D\end{array}$ & $\begin{array}{c}\text { Number of } \\
\text { micelles } \\
M\end{array}$ & $\begin{array}{c}\text { Aggregation } \\
\text { number } \\
N\end{array}$ \\
\hline $1 \mathrm{wt} \% \mathrm{BSA}+40 \mathrm{mM}$ SDS & 18.6 & 37.8 & 1.70 & 5 & 52 \\
\hline $1 \mathrm{wt} \% \mathrm{BSA}+40 \mathrm{mM}$ DTAB & 16.8 & 56.2 & 1.82 & 8 & 34 \\
\hline
\end{tabular}

\section{B. Characterization of mixed protein and surfactant systems}

\section{Role of ionic strength}

Figure 2(a) shows SANS data of 1 wt \% BSA protein with $40 \mathrm{mM}$ SDS and in the presence of varying salt concentration ( 0 to $0.5 \mathrm{M} \mathrm{NaCl}$ ). The scattering depends on the form factor and structure factor contributions. The presence of salt can change each of these factors and hence the change in the scattering data. The structure factor contribution can arise from the protein-protein, protein-micelle, and micelle-micelle interactions $[48,50]$. It is difficult to calculate a reliable structure factor from the existing models for such multicomponent systems. Therefore, the presence of salt is used to minimize the contributions of the structure factor, in particular for charged colloidal systems [50]. There is also the possibility that the modification in the protein-surfactant interaction modifies their complex structure [17]. The lower value of scattering in the low $Q$ range of the SANS data in the absence of salt suggests the contribution of the structure factor in the data. The data of salt concentrations at $0.2 \mathrm{M} \mathrm{NaCl}$ and above almost become flat in the low- $Q$ region, where probably the structure factor contribution between protein-surfactant complexes has been suppressed [50]. Therefore, the salt concentration of $0.2 \mathrm{M} \mathrm{NaCl}$ was fixed in all the experiments for examining the interaction of BSA protein with SDS surfactant. The effects of salt in the SANS data of 1 wt \% BSA protein with $40 \mathrm{mM}$ DTAB and $40 \mathrm{mM} \mathrm{C12E10} \mathrm{are} \mathrm{shown} \mathrm{in} \mathrm{Figs.} \mathrm{2(b)} \mathrm{and} \mathrm{2(c),}$ respectively. These data, unlike those of SDS, do not show any significant changes in the scattering with the variation in salt concentration. In the case of BSA with DTAB, it could be because of the charge neutralization by the strong interaction of the two oppositely components in forming their complexes. On the other hand, for nonionic surfactants as expected no noticeable effect of salt is observed [26,51]. The small differences in Figs. 2(b) and 2(c) are not systematic and seem to be statistical. The interaction of protein with different surfactants (SDS, DTAB, and C12E10) has been therefore compared under the same solution condition of $0.2 \mathrm{M} \mathrm{NaCl}$.

\section{Effect of different surfactants}

SANS data of 1 wt $\%$ BSA protein with $40 \mathrm{mM}$ of each of anionic SDS, cationic DTAB, and nonionic C12E10 surfactants are shown in Fig. 3. The scattering features of protein-surfactant systems are significantly different for different surfactants. It is observed that for ionic surfactants the scattering of the protein-surfactant complex is very different from the sum of the individual components. However, the scattering of a protein-surfactant complex with nonionic surfactant matches sum of the individual components. This indicates strong interaction of proteins with ionic surfactants (both anionic and cationic) and almost no interaction of proteins with the nonionic surfactant [26,51]. The similar kind of interaction of the anionic protein BSA with anionic surfactant SDS and cationic surfactant DTAB can be interpreted as a

TABLE III. (a) Fitted parameters of DLS data of individual components of BSA protein and surfactants (anionic SDS, cationic DTAB, and nonionic $\mathrm{C} 12 \mathrm{E} 10$ ) at $p \mathrm{H}=7$ and $0.2 \mathrm{M} \mathrm{NaCl}$ in $\mathrm{D}_{2} \mathrm{O}$. The results of DLS data (hydrodynamic radii) are also compared with those of the SANS data (effective radii). The numbers in the parentheses of the hydrodynamic radii are the values of the polydispersity index of the systems. (b) Fitted parameters of DLS data of protein-surfactant systems at $p \mathrm{H}=7$ and $0.2 \mathrm{M} \mathrm{NaCl}$ in $\mathrm{D}_{2} \mathrm{O}$. The results of DLS data (hydrodynamic radii) are also compared with those of the SANS data (correlation length).

\begin{tabular}{|c|c|c|c|}
\hline System & $\begin{array}{l}\text { Diffusion coefficient } \\
D\left(10^{-8} \mathrm{~cm}^{2} \mathrm{~s}^{-1}\right)\end{array}$ & $\begin{array}{c}\text { Hydrodynamic radius } \\
R_{h}(\AA)\end{array}$ & $\begin{array}{c}\text { Effective radius }^{\mathrm{a}} \\
(\AA)\end{array}$ \\
\hline \multicolumn{4}{|c|}{ (a) } \\
\hline $40 \mathrm{mM}$ SDS & 81.2 & $26.5(0.13)$ & 25.1 \\
\hline 40 mM DTAB & 86.1 & $25.0(0.10)$ & 23.1 \\
\hline $40 \mathrm{mM} \mathrm{C} 12 \mathrm{E} 10$ & 56.6 & $38.0(0.11)$ & 29.5 \\
\hline $1 \mathrm{wt} \% \mathrm{BSA}$ & 53.8 & $40.0(0.10)$ & 29.0 \\
\hline System & $\begin{array}{l}\text { Diffusion coefficient } \\
\qquad D\left(10^{-8} \mathrm{~cm}^{2} \mathrm{~s}^{-1}\right)\end{array}$ & $\begin{array}{l}\text { Hydrodynamic } \\
\text { radius } R_{h}(\AA)\end{array}$ & $\begin{array}{c}\text { Correlation length }^{\mathrm{b}} \\
\xi(\AA) \\
\end{array}$ \\
\hline \multicolumn{4}{|c|}{ (b) } \\
\hline $1 \mathrm{wt} \% \mathrm{BSA}+40 \mathrm{mM}$ SDS & 36.5 & $59.0(0.13)$ & 37.8 \\
\hline $1 \mathrm{wt} \% \mathrm{BSA}+40 \mathrm{mM}$ DTAB & 34.7 & $62.0(0.13)$ & 56.2 \\
\hline
\end{tabular}

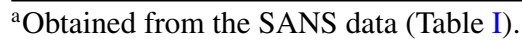

${ }^{\mathrm{b}}$ Obtained from the SANS data (Table II). 

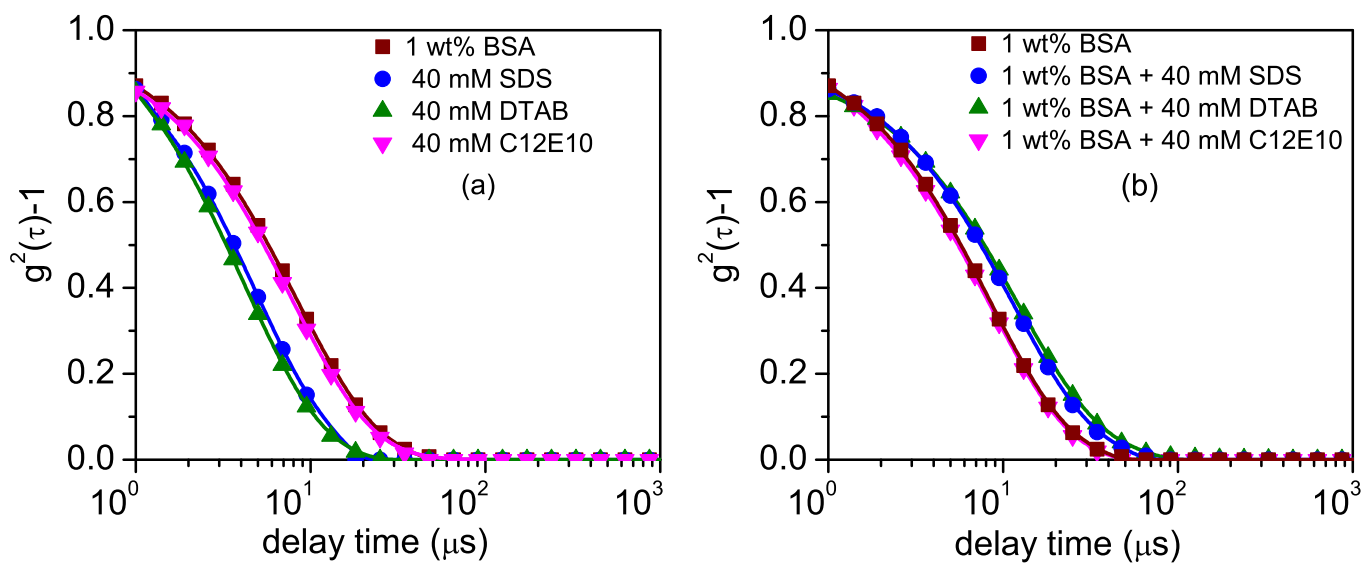

FIG. 4. (Color online) (a) DLS data from individual components of $1 \mathrm{wt} \%$ BSA protein and $40 \mathrm{mM}$ surfactants (anionic SDS, cationic $\mathrm{DTAB}$, and nonionic C12E10) at $p \mathrm{H}=7$ and $0.2 \mathrm{M} \mathrm{NaCl}$ in $\mathrm{D}_{2} \mathrm{O}$. (b) DLS data from protein-surfactant complexes of $1 \mathrm{wt} \% \mathrm{BSA}+40 \mathrm{mM}$ SDS, 1 wt $\% \mathrm{BSA}+40 \mathrm{mM} \mathrm{DTAB}$, and $1 \mathrm{wt} \% \mathrm{BSA}+40 \mathrm{mM} \mathrm{C} 12 \mathrm{E} 10$ at $p \mathrm{H}=7$ and $0.2 \mathrm{M} \mathrm{NaCl}$ in $\mathrm{D}_{2} \mathrm{O}$.

result of site-specific electrostatic binding of surfactant on the oppositely charged patches of the protein [22,25,26,51]. The SANS data of protein-surfactant systems for ionic surfactants show linearity in the intermediate- $Q$ region, which indicates the formation of fractal structure of their complexes [5,6,41]. This fractal structure is modeled by the bead-necklace model of protein-surfactant complexes, representing the micellelike clusters formed along the unfolded polypeptide chain of protein [5-7]. The high- $Q$ cutoff, low- $Q$ cutoff, and slope of linearity in SANS data are decided by the building block size (the micellelike cluster), correlation length (overall size of the complex), and fractal dimension (packing of micelles) of the protein-surfactant complex, respectively $[5,6,52]$. The slope of the data in the linear- $Q$ range is observed to be between 1 and 3. Therefore, $S(Q)$ of the mass fractal along with $P(Q)$ of the spherical micelles have been used in analyzing the scattering profiles $[17,33]$. The fitted parameters are given in Table II. There are notable differences in the data for the protein complex with the two ionic surfactants. The building block size is smaller and the overall size of the complex is larger for the case of cationic surfactant (DTAB) than for the anionic surfactant (SDS). A possible reason for these differences is the site-specific electrostatic binding of cationic and anionic surfactants with different oppositely charged patches on anionic BSA protein. Since there are more negative patches for the binding of cationic surfactant than anionic surfactant, it will lead to a larger number of cationic DTAB micelles than anionic SDS micelles attached to protein $[51,53,54]$. The smaller number of micelles for anionic SDS will require a larger amount of unfolded protein to pack within the individual micelles, which thereby increases the size of the micelles. The correlation length representing the overall size of the protein-surfactant complex is higher for DTAB than for SDS as more micelles attached to the protein for DTAB [51]. The higher number of micelles attached to protein also make the structure of complex more compact as evident from the higher value of its fractal dimension for DTAB than SDS. There is no significant interaction observed of protein with the nonionic surfactant C12E10 and the data are fitted with the sum of the scattering from individual components [26,51]. These results (protein complexes with different surfactants)

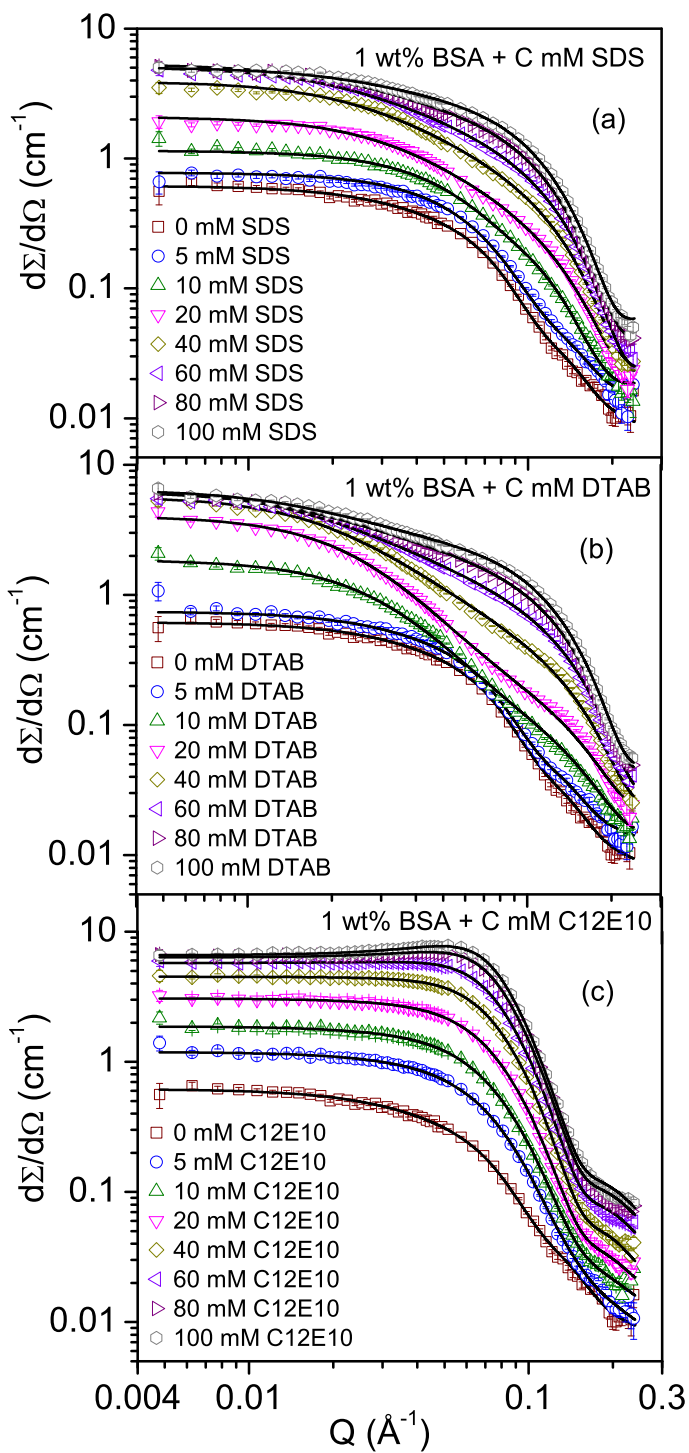

FIG. 5. (Color online) SANS data of 1 wt \% BSA protein with varying concentration of surfactants [(a) anionic SDS, (b) cationic DTAB, and (c) nonionic C12E10] at $p \mathrm{H}=7$ and $0.2 \mathrm{M} \mathrm{NaCl}$ in $\mathrm{D}_{2} \mathrm{O}$. 
show that the charge state of the surfactant can be used to tune the structure of protein-surfactant complexes.

DLS has been used as a complementary technique to SANS for examining protein-surfactant complexes. DLS data of the individual protein (1 wt \% BSA) and micelles $(40 \mathrm{mM}$ anionic SDS, cationic DTAB, and nonionic C12E10) are shown in Fig. 4(a). The differences in the decay of the intensity autocorrelation function $g^{2}(\tau)$ correspond to the different values of diffusion coefficients in these systems $[42,43]$. The decay of the intensity autocorrelation function of BSA protein is found to be slower than those of all three different micelles. It follows the trend in the decreasing order of the intensity autocorrelation function $\mathrm{DTAB}>\mathrm{SDS}>\mathrm{C} 12 \mathrm{E} 10$ for different micelles. The values of hydrodynamic radii for these systems as calculated using the Stokes-Einstein relation [Eq. (15)] are given in Table III. It is observed that the hydrodynamic sizes obtained from DLS are larger than the effective sizes of the individual components from SANS. This is consistent with the fact that proteins and micelles are fairly hydrated and thus have higher values of the hydrodynamic sizes [55]. Figure 4(b) shows the intensity autocorrelation functions of protein-surfactant complexes. In the case of nonionic surfactant, the intensity autocorrelation function of the protein-surfactant complex is the same as that of the protein. This observation along with the fact that the individual protein and nonionic surfactant have almost similar intensity autocorrelation functions [Fig. 3(a)] supports noninteraction of the two components, as consistent with the SANS results [51]. The decay of the intensity autocorrelation function of protein-surfactant complexes for ionic surfactants is slowed because of the strong interaction of protein and surfactant forming a larger structure [17,19,51]. The hydrodynamic sizes of these complexes are compared with the correlation length of the bead-necklace structure of the complexes by SANS. The hydrodynamic sizes are again larger than those from
SANS analysis because of the hydration associated with the complexes.

\section{Role of surfactant concentration}

The effect of surfactant concentration on protein-surfactant interaction is examined in Fig. 5. The figure shows SANS data of $1 \mathrm{wt} \%$ BSA protein with varying concentration (0-100 $\mathrm{mM}$ ) of each of the surfactants (anionic SDS, cationic DTAB, and nonionic $\mathrm{C} 12 \mathrm{E} 10)$. The features of the data for ionic surfactants (anionic and cationic) are same irrespective of the different charge state of the surfactant. The data for nonionic surfactant are different from that with ionic surfactant. The scattering of protein-surfactant complexes for ionic surfactant can be divided into three regions (specific binding, cooperative binding, and saturation) $[7,19,33]$. In specific binding region (low surfactant concentrations), the surfactant molecules bind to the oppositely charged patches on protein through electrostatic interaction but retaining its folded structure. In cooperative binding region (intermediate surfactant concentrations), the interaction of surfactant with protein is enhanced because of the dominance of hydrophobic interaction leading to micellelike clusters forming along the unfolded polypeptide chain of protein. In the saturation region (high surfactant concentrations), the excess of surfactant does not bind to the protein. The free surfactant thereafter coexists as micelles with the protein-surfactant complexes in the saturation region [33]. The fitted parameters of the protein-surfactant complexes as a function of ionic surfactant concentration are given in Table IV. The correlation length (extent of unfolding) increases and the fractal dimension (packing of micelles in the proteinsurfactant complex) decreases with the increase in both anionic and cationic surfactant concentration $[5,6]$. The micelle size remains the same whereas the surfactant aggregation number decreases as the unfolded protein component in micelles is

TABLE IV. (a) Fitted parameters of SANS data of protein-surfactant system (1 wt $\%$ BSA $+C$ mM SDS) characterized by mass fractal structure representing bead-necklace model of their complexes. (b) Fitted parameters of SANS data of protein-surfactant system (1 wt \% $\mathrm{BSA}+C$ mM DTAB) characterized by mass fractal structure representing bead-necklace model of their complexes.

\begin{tabular}{|c|c|c|c|c|c|c|}
\hline System & $\begin{array}{c}\text { Micelle } \\
\text { radius } \\
r(\AA)\end{array}$ & $\begin{array}{c}\text { Correlation } \\
\text { length } \\
\xi(\AA) \\
\end{array}$ & $\begin{array}{c}\text { Fractal } \\
\text { dimension } \\
D \\
\end{array}$ & $\begin{array}{c}\text { Number of } \\
\text { micelles } \\
M \\
\end{array}$ & $\begin{array}{c}\text { Aggregation } \\
\text { number } \\
N \\
\end{array}$ & $\begin{array}{c}\text { Free micelle } \\
\text { concentration } \\
(\mathrm{mM})\end{array}$ \\
\hline \multicolumn{7}{|c|}{ (a) } \\
\hline $10 \mathrm{mM}$ SDS & 18.6 & 22.0 & 2.41 & 1 & 63 & 0 \\
\hline $20 \mathrm{mM}$ SDS & 18.6 & 28.0 & 2.05 & 2 & 58 & 0 \\
\hline $40 \mathrm{mM}$ SDS & 18.6 & 37.8 & 1.70 & 5 & 52 & 0 \\
\hline $60 \mathrm{mM}$ SDS & 18.6 & 46.5 & 1.50 & 6 & 49 & 15 \\
\hline 80 mM SDS & 18.6 & 47.6 & 1.42 & 7 & 47 & 32 \\
\hline $100 \mathrm{mM}$ SDS & 18.6 & 49.8 & 1.36 & 8 & 46 & 47 \\
\hline \multicolumn{7}{|c|}{ (b) } \\
\hline 10 mM DTAB & 16.8 & 24.9 & 2.80 & 2 & 38 & 0 \\
\hline 20 mM DTAB & 16.8 & 36.1 & 2.46 & 4 & 35 & 0 \\
\hline 40 mM DTAB & 16.8 & 56.2 & 1.82 & 8 & 34 & 0 \\
\hline $60 \mathrm{mM}$ DTAB & 16.8 & 62.0 & 1.55 & 9 & 32 & 15 \\
\hline 80 mM DTAB & 16.8 & 63.4 & 1.49 & 10 & 31 & 33 \\
\hline $100 \mathrm{mM}$ DTAB & 16.8 & 65.2 & 1.42 & 11 & 30 & 50 \\
\hline
\end{tabular}




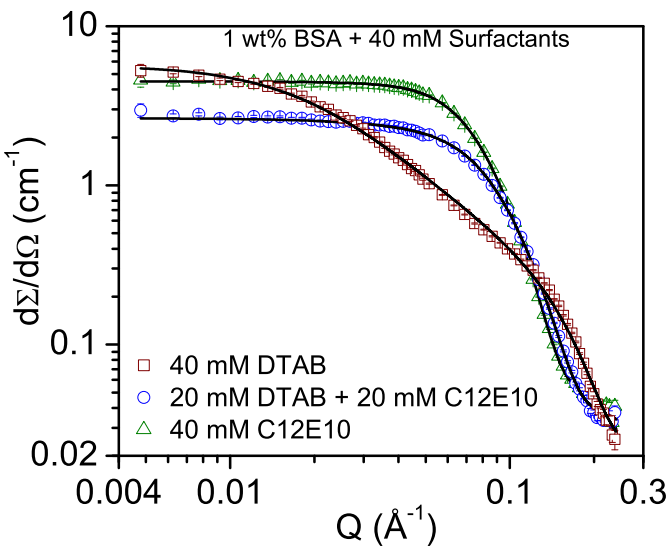

FIG. 6. (Color online) SANS data of $1 \mathrm{wt} \%$ BSA protein with mixed-surfactants $(20 \mathrm{mM}$ DTAB and $20 \mathrm{mM} \mathrm{C12E10)} \mathrm{system} \mathrm{at}$ $p \mathrm{H}=7$ and $0.2 \mathrm{M} \mathrm{NaCl}$ in $\mathrm{D}_{2} \mathrm{O}$. For comparison the data of $1 \mathrm{wt} \%$ BSA protein with $40 \mathrm{mM}$ DTAB and $40 \mathrm{mM} \mathrm{C12E} 10$ alone are also given.

increased. Both the surfactants show binding saturation at almost similar surfactant concentrations $(\sim 45 \mathrm{mM}$ SDS or DTAB) $[7,56]$. There is no interaction of protein with the nonionic surfactant C12E10 over the whole concentration range of surfactant, and the data are fitted with the sum of the scattering contributions from protein and micelles. The buildup of the correlation peak at higher C12E10 concentrations indicates the contribution from intermicelle correlations.

\section{Effect of mixed surfactants}

We have observed that the interaction of protein with ionic and nonionic surfactants is very different. An ionic surfactant, irrespective of its charge nature, can unfold the protein, whereas the nonionic surfactant does not alter the native structure of the protein. The effect of these two types of surfactants (ionic and nonionic) together with protein has been examined. The data for 1 wt $\%$ BSA with a mixed surfactant system of $20 \mathrm{mM}$ DTAB and $20 \mathrm{mM} \mathrm{C} 12 \mathrm{E} 10$ are compared with those for $1 \mathrm{wt} \%$ BSA with $40 \mathrm{mM}$ DTAB and 1wt\% BSA with $40 \mathrm{mM} \mathrm{C12E} 10$ in Fig. 6. The scattering features of the protein with mixed surfactants are very different from those of the protein-ionic surfactant system but similar to those of the protein-nonionic surfactant system. The linearity in the intermediate- $Q$ range of the protein-ionic surfactant system is completely diminished in the case of the mixed surfactants system and attains features close to those of the protein with nonionic surfactant alone. Three possible models can be considered for the interactions in these mixed systems. (i) Only the ionic surfactant interacts with the protein. This leads to ionic-surfactant-induced unfolding of proteins, which coexists with noninteracting nonionic micelles. (ii) Both ionic and nonionic surfactants interact with the protein. The system primarily consists of mixed-surfactantinduced unfolded proteins. (iii) None of the surfactant interacts with the protein. In this case, the system will have folded protein coexisting with mixed micelles. The comparison of scattering from these different models with experimental data is shown in Figs. 7(a)-7(c). Figure 7(a) compares the

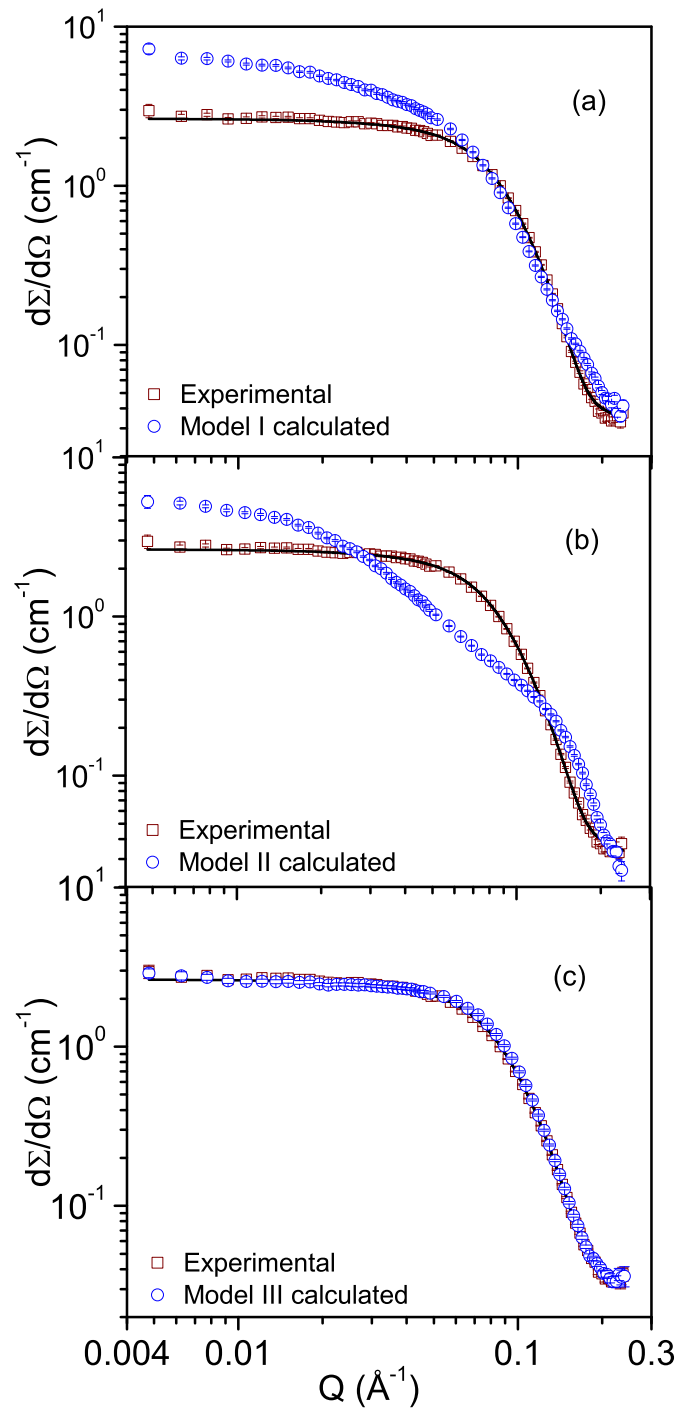

FIG. 7. (Color online) The comparison of model scattering with the experimental data of $1 \mathrm{wt} \%$ BSA protein with mixed-surfactants (20 mM DTAB and $20 \mathrm{mM} \mathrm{C12E10)} \mathrm{system} \mathrm{at} p \mathrm{H}=7$ and $0.2 \mathrm{M} \mathrm{NaCl}$ in $\mathrm{D}_{2} \mathrm{O}$. (a) Model I: Nonionic micelles coexist with the complexes of protein-ionic surfactant; (b) model II: protein forms complexes with mixed ionic and nonionic surfactants; and (c) model III: native protein coexists with mixed micelles of ionic and nonionic surfactants. The model calculations are done using the experimental data of different individual and mixed components.

scattering from the protein-mixed-surfactants system with the sum of the experimental scattering from the proteinionic surfactant and nonionic micelles. The vast difference between the model and measured scattering curves rules out the possibility of coexistence of noninteracting nonionic surfactant and interacting ionic surfactant with protein. The model scattering of protein interaction via mixed micelles of ionic and nonionic surfactants also does not match the experimental data [Fig. 7(b)]. The experimental data match the model scattering of noninteracting micelles of ionic and nonionic surfactants coexisting with the unperturbed folded protein [Fig. 7(c)]. The data in Fig. 6 have therefore been fitted with the model of native folded protein coexisting with 

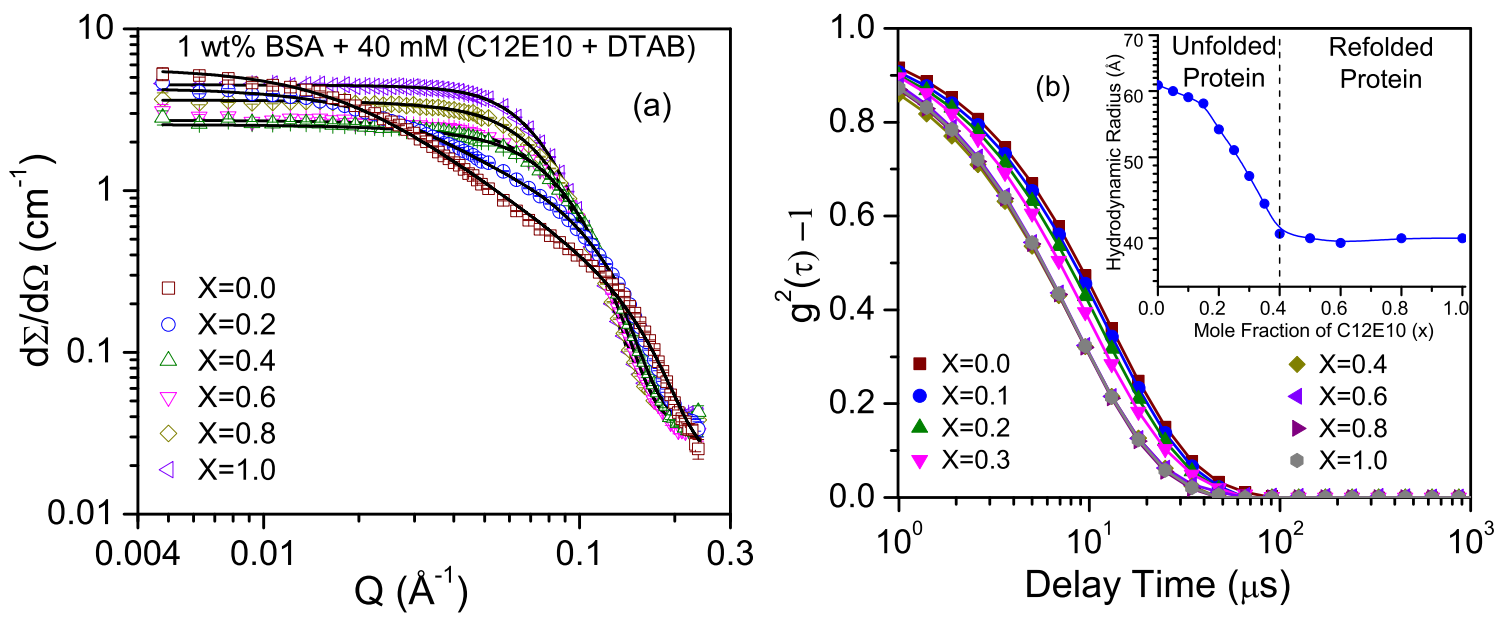

FIG. 8. (Color online) (a) SANS and (b) DLS data of $1 \mathrm{wt} \%$ BSA protein with $40 \mathrm{mM}$ of mixed surfactants (DTAB and C12E10) with varying mole fraction $(X)$ of nonionic surfactant at $p \mathrm{H}=7$ and $0.2 \mathrm{M} \mathrm{NaCl}$ in $\mathrm{D}_{2} \mathrm{O}$. The inset in (b) shows the variation of the effective hydrodynamic radius with the change in the mole fraction of nonionic surfactant.

mixed micelles of ionic and nonionic surfactants. It is an interesting observation that the presence of nonionic surfactant changes an ionic surfactant from interacting to noninteracting with the protein. This mechanism can be understood based on the competition of charge-driven binding of the ionic surfactant with protein with that of hydrophobic-driven mixed micellization of ionic surfactant with nonionic surfactant. Our results show that the dominance of hydrophobic interaction of ionic and nonionic surfactants over the electrostatic binding of ionic surfactant with protein governs the structure of these systems.

Figure 8(a) shows the SANS data of 1 wt $\%$ BSA protein with $40 \mathrm{mM}$ of mixed cationic DTAB-nonionic C12E10 surfactants with varying mole fraction of C12E10 surfactants. In these systems $\mathrm{C} 12 \mathrm{E} 10$ was added to BSA-DTAB. It is clearly visible that the interaction of protein with mixed surfactants depends on the mole fraction of the nonionic surfactant. The scattering features of the protein-mixed surfactant complex are similar to those of the protein-ionic surfactant complex up to 0.2 mole fraction of nonionic surfactant, whereas the data for 0.4 mole fraction and beyond resemble those of the protein-nonionic surfactant system. These data have been used to model the nonionic-surfactant-dependent modification in the interaction of ionic surfactant with the protein. The data suggest that the binding of ionic surfactant to protein decreases with the increase in the concentration of nonionic surfactant. This has been modeled through the decrease in the number of micelles attached to unfolded protein in the protein-ionic surfactant complex as the concentration of nonionic surfactant is increased (Table V). The number of ionic micelles attached to unfolded protein decreases by about $50 \%$ for the 0.2 mole fraction of nonionic surfactant, whereas all the ionic micelles detached for 0.4 mole fraction and beyond to form a mixed micelle with the nonionic surfactant. These results have been further confirmed by the DLS measurements. Figure 8(b) shows the variation in intensity autocorrelation function with the change in the mole fraction of nonionic surfactant in the protein-mixed surfactants system. The decay of the intensity autocorrelation function becomes faster, indicating detachment of the ionic micelles from the protein-ionic surfactant complex with the increase in the mole fraction of nonionic surfactant. The change in the effective hydrodynamic size of the system with varying mole fraction of nonionic surfactant is plotted in the inset of Fig. 8(b). The hydrodynamic size decreases up to 0.4 mole fraction of nonionic surfactant and thereafter remains constant and equal to that of the folded protein. The effect of addition of $\mathrm{C} 12 \mathrm{E} 10$ to BSA-SDS is also found similar to that of BSA-DTAB. Thus, both the SANS and DLS techniques independently confirm the nonionic-surfactantdependent refolding of the ionic-surfactant-induced unfolded protein. We have also observed that the interaction of protein with the mixed-surfactants system is independent of the order in which the two surfactants (ionic and nonionic) are added (Fig. 9). This in turn shows that the presence of a nonionic surfactant can be used to refold an unfolded protein (nonionic

TABLE V. Fitted parameters of SANS data of protein-mixed surfactant system (1 wt $\%$ BSA + 40 mM DTAB-C12E10) characterized by mass fractal structure representing bead-necklace model of protein-ionic surfactant complex coexisting with mixed micelles. For mole fraction of nonionic surfactant 0.4 and beyond, the protein-mixed surfactant system consist of refolded protein back to native structure coexisting with fully $(100 \%)$ free mixed micelles.

\begin{tabular}{|c|c|c|c|c|c|c|}
\hline $\begin{array}{l}\text { Mole } \\
\text { fraction of } \\
\text { C12E10 }\end{array}$ & $\begin{array}{l}\text { Micelle } \\
\text { radius } \\
r(\AA)\end{array}$ & $\begin{array}{l}\text { Correlation } \\
\text { length } \\
\xi(\AA)\end{array}$ & $\begin{array}{c}\text { Fractal } \\
\text { dimension } \\
D\end{array}$ & $\begin{array}{c}\text { Number of } \\
\text { micelles attached } \\
M\end{array}$ & $\begin{array}{c}\text { Aggregation } \\
\text { number } \\
N\end{array}$ & $\begin{array}{l}\text { Fraction of } \\
\text { free mixed } \\
\text { micelles }(\%)\end{array}$ \\
\hline 0 & 16.8 & 56.2 & 1.82 & 8 & 36 & 0 \\
\hline 0.2 & 16.8 & 31.7 & 2.32 & 4 & 37 & 48 \\
\hline
\end{tabular}




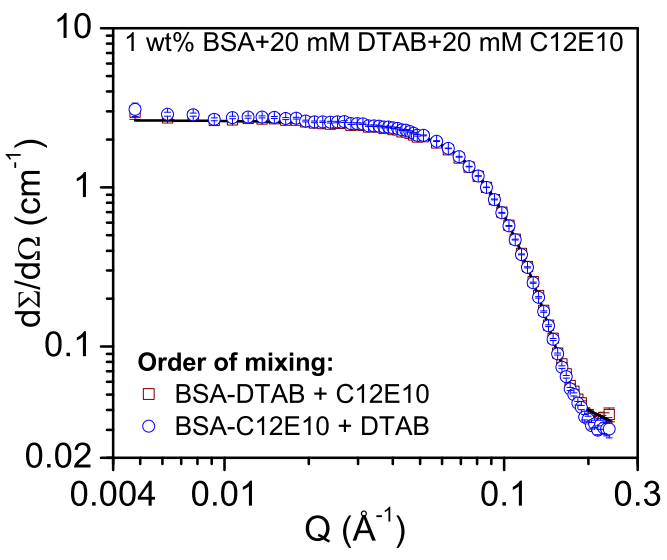

FIG. 9. (Color online) SANS data of $1 \mathrm{wt} \%$ BSA protein with $40 \mathrm{mM}$ of mixed surfactants (DTAB and C12E10) at 1:1 mole fraction of ionic and nonionic surfactants at $p \mathrm{H}=7$ and $0.2 \mathrm{M} \mathrm{NaCl}$ in $\mathrm{D}_{2} \mathrm{O}$. The data are compared with a change in the order of mixing of ionic and nonionic surfactants.

surfactant addition to the protein-ionic surfactant system) as well as to prevent ionic-surfactant-induced unfolding of the protein using a nonionic surfactant (ionic surfactant addition to the protein-nonionic surfactant system)

\section{CONCLUSIONS}

The role of different surfactants, concentration of surfactant, ionic strength, and mixed surfactants on proteinsurfactant interaction and the resultant structure of the complexes has been studied by the scattering techniques SANS and DLS. The ionic and nonionic surfactants show very different interactions with the protein. The ionic surfactants bind to the protein by site-specific electrostatic interaction and form micellelike clusters along the unfolded protein chain. On the other hand, nonionic surfactants do not interact with the protein and coexist independently with the unperturbed folded protein. The interaction of protein and ionic surfactant can be enhanced by increasing the ionic strength and/or surfactant concentration. Further, the interaction of protein with mixed surfactants can be used to fold back unfolded protein as well as to prevent ionic-surfactant-induced protein unfolding. This behavior is explained as a result of the dominance of hydrophobic interaction of mixed surfactants over the electrostatic binding of ionic surfactant with protein.
[1] E. D. Goddard and K. P. Ananthapadmanabhan, Interactions of Surfactants with Polymers and Proteins (CRC, London, 1993).

[2] D. Otzen, Biochim. Biophys. Acta. 1814, 562 (2011).

[3] M. N. Jones, Chem. Soc. Rev. 21, 127 (1992).

[4] J. Narayanan and V. W. Deotare, Phys. Rev. E 60, 4597 (1999).

[5] S.-H. Chen and J. Teixeira, Phys. Rev. Lett. 57, 2583 (1986).

[6] S. Chodankar, V. K. Aswal, J. Kohlbrecher, R. Vavrin, and A. G. Wagh, J. Phys.: Condens. Matter 19, 326102 (2007).

[7] N. J. Turro, X.-G. Lei, K. P. Ananthapadmanabhan, and M. Aronson, Langmuir 11, 2525 (1995).

[8] X.-H. Guo and S.-H. Chen, Phys. Rev. Lett. 64, 2579 (1990).

[9] R. Piazza, M. Pierno, E. Vignati, G. Venturoli, F. Francia, A. Mallardi, and G. Palazzo, Phys. Rev. Lett. 90, 208101 (2003).

[10] M. Ospinal-Jiménez and D. C. Pozzo, Langmuir 30, 1351 (2014).

[11] H. J. Lee, A. McAuley, K. F. Schilke, and J. McGuire, Adv. Drug Deliv. Rev. 63, 1160 (2011).

[12] A. Fiechter, Trends Biotechnol. 10, 208 (1992).

[13] R. Petkova, S. Tcholakova, and N. D. Denkov, Langmuir 28, 4996 (2012).

[14] P. Khullar, V. Singh, A. Mahal, P. N. Dave, S. Thakur, G. Kaur, J. Singh, S. Singh Kamboj, and M. Singh Bakshi, J. Phys. Chem. C 116, 8834 (2012).

[15] S. Chodankar, V. K. Aswal, J. Kohlbrecher, R. Vavrin, and A. G. Wagh, Phys. Rev. E 77, 031901 (2008).

[16] V. K. Aswal, S. Chodankar, J. Kohlbrecher, R. Vavrin, and A. G. Wagh, Phys. Rev. E 80, 011924 (2009).

[17] S. Chodankar, V. K. Aswal, P. A. Hassan, and A. G. Wagh, Physica B 398, 112 (2007).

[18] C. A. Nelson, J. Biol. Chem. 246, 3895 (1971).

[19] A. Valstar, M. Almgren, W. Brown, and M. Vasilescu, Langmuir 16, 922 (2000).
[20] N. Deo, S. Jockusch, N. J. Turro, and P. Somasundaran, Langmuir 19, 5083 (2003).

[21] X. L. Zhang, J. Penfold, R. K. Thomas, I. M. Tucker, J. T. Petkov, J. Bent, A. Cox, and I. Grillo, Langmuir 27, 10514 (2011).

[22] T. Chakraborty, I. Chakraborty, S. P. Moulik, and S. Ghosh, Langmuir 25, 3062 (2009).

[23] B. Nieto-Ortega, J. M. Hierrezuelo, C. Carnero Ruiz, J. T. López Navarrete, J. Casado, and F. J. Ramírez, J. Phys. Chem. Lett. 5, 8 (2014).

[24] D. Kelley and D. J. McClements, Food Hydrocolloids 17, 73 (2003).

[25] E. L. Gelamo, R. Itri, A. Alonso, J. V. da Silva, and M. Tabak, J. Colloid Interface Sci. 277, 471 (2004).

[26] A. D. Nielsen, K. Borch, and P. Westh, Biochim. Biophys. Acta 1479, 321 (2000).

[27] U. Anand and S. Mukherjee, Phys. Chem. Chem. Phys. 15, 9375 (2013).

[28] A. Rogozea, I. Matei, I. M. Turcu, G. Ionita, V. E. Sahini, and A. Salifoglou, J. Phys. Chem. B 116, 14245 (2012).

[29] T. Serno, R. Geidobler, and G. Winter, Adv. Drug Deliv. Rev. 63, 1086 (2011).

[30] K. K. Andersen and D. E. Otzen, J. Phys. Chem. B 113, 13942 (2009).

[31] M. A. Mir, N. Gull, J. M. Khan, R. H. Khan, A. A. Dar, and G. M. Rather, J. Phys. Chem. B 114, 3197 (2010).

[32] S. Mehan, V. K. Aswal, and J. Kohlbrecher, Langmuir 30, 9941 (2014).

[33] S. Mehan, A. J. Chinchalikar, S. Kumar, V. K. Aswal, and R. Schweins, Langmuir 29, 11290 (2013).

[34] J. Kohlbrecher and W. Wagner, J. Appl. Crystallogr. 33, 804 (2000).

[35] U. Keiderling, Appl. Phys. A 74, s1455 (2002). 
[36] S.-H. Chen and T.-L. Lin, in Methods in Experimental Physics, edited by D. L. Price and K. Skold (Academic Press, New York, 1987), p. 489.

[37] J. B. Hayter and J. Penfold, Colloid Polym. Sci. 261, 1022 (1983).

[38] J. S. Pedersen, J. Appl. Crystallogr. 33, 637 (2000).

[39] J. S. Pedersen, Adv. Colloid Interface Sci. 70, 171 (1997).

[40] J. B. Hayter and J. Penfold, Mol. Phys. 42, 109 (1981).

[41] J. Teixeira, J. Appl. Crystallogr. 21, 781 (1988).

[42] R. Pecora, Dynamic Light Scattering: Applications of Photon Correlation Spectroscopy (Plenum, New York, 1985).

[43] P. A. Hassan, S. Rana, and G. Verma, Langmuir 31, 3 (2015).

[44] B. J. Frisken, Appl. Opt. 40, 4087 (2001).

[45] D. E. Koppel, J. Chem. Phys. 57, 4814 (1972).

[46] F. Zhang, F. Roosen-Runge, M. W. A. Skoda, R. M. J. Jacobs, M. Wolf, Ph. Callow, H. Frielinghaus, V. Pipich, S. Prévost, and F. Schreiber, Phys. Chem. Chem. Phys. 14, 2483 (2012).

[47] V. K. Aswal and P. S. Goyal, Phys. Rev. E 67, 051401 (2003).
[48] S. Kumar, V. K. Aswal, and J. Kohlbrecher, Langmuir 28, 9288 (2012).

[49] W. Warisnoicharoen, A. B. Lansley, and M. J. Lawrence, AAPS PharmSci 2, 16 (2000).

[50] M. Ospinal-Jiménez and D. C. Pozzo, Langmuir 27, 928 (2011).

[51] X. Zhang, A. Poniewierski, S. Hou, K. Sozanski, A. Wisniewska, S. A. Wieczorek, T. Kalwarczyk, L. Sun, and R. Holyst, Soft Matter 11, 2512 (2015).

[52] J. M. Franklin, L. N. Surampudi, H. S. Ashbaugh, and D. C. Pozzo, Langmuir 28, 12593 (2012).

[53] A. Lee, S. K. Y. Tang, C. R. Mace, and G. M. Whitesides, Langmuir 27, 11560 (2011).

[54] M. Vasilescu, D. Angelescu, M. Almgren, and A. Valstar, Langmuir 15, 2635 (1999).

[55] E. A. Mun, C. Hannell, S. E. Rogers, P. Hole, A. C. Williams, and V. V. Khutoryanskiy, Langmuir 30, 308 (2014).

[56] S. F. Santos, D. Zanette, H. Fischer, and R. Itri, J. Colloid Interface Sci. 262, 400 (2003). 